Editorial

\title{
Changing Perspectives on the Economics of Water
}

\section{Davide Viaggi ${ }^{1, *}$, Giacomo Zanni ${ }^{2, \dagger}$ and Meri Raggi ${ }^{3, \dagger}$}

1 Department of Agricultural Sciences, University of Bologna, Viale Fanin 44, Bologna 40127, Italy

2 ENDIF-Engineering Department In Ferrara, University of Ferrara, Via Saragat, Ferrara 144100 , Italy; E-Mail: giacomo.zanni@unife.it

3 Department of Statistical Sciences, University of Bologna, Via Belle Arti, 41, Bologna 40126, Italy; E-Mail: meri.raggi@unibo.it

$\dagger$ These authors contributed equally to this work.

* Author to whom correspondence should be addressed; E-Mail: davide.viaggi@unibo.it; Tel.: +39-051-209-6114; Fax: +39-051-209-6105.

External Editor: Miklas Scholz

Received: 2 September 2014; in revised form: 24 September 2014 / Accepted: 24 September 2014 / Published: 30 September 2014

\begin{abstract}
This paper provides an overview of the special issue on "Water policy, productivity and economic efficiency". In particular, it includes an overview of key topics on the future of water as a productive factor, in the context of alternative uses and perspective scenarios. The selected papers cover a wide range of relevant economic issues and are presented in three categories: productivity assessment, institutional framework and mechanisms, and governance aspects. The paper concludes by discussing future research challenges in this field.
\end{abstract}

Keywords: water policy design; economic efficiency and productivity; water markets; climate change; evaluation instruments

\section{Introduction}

Over the past few decades, water policies have undergone significant changes in many countries notably due to the development of national and international political, social and environmental issues, 
including globalisation, trade liberalisation, institutional and legal requirements, changing standards of living, management practices and technological innovation. Policy changes include both "high level" views about water status and practical instruments, in particular with an emphasis on integrated basin management and economic policy instruments.

Since 1992, in virtue of the Dublin Statements, the international community has officially recognised water as a scarce resource. Specifically, it has been asserted that water resources are vulnerable and not infinite [1].

In particular, Principle 4 of these statements defines water as an economic good. On the other hand, the first principle of the 1992 Rio Statements [2], that supplemented the Dublin Principles, implies that water is also a social good (for a "healthy and productive life, in harmony with nature"). It follows that the humans are entitled to at least certain levels of water, in terms of both quantity and quality, and from a point of view of both environmental and productive uses, under the responsibility of their respective governments $[3,4]$.

A relevant part of the water policy literature addresses this topic mainly as an issue related to environmental conservation. However, water remains a major productive factor, particularly in agriculture. This role is made even more prominent in light of economic crises, increased competition across markets and climate change, as well as fossil energy limitations, which also highlight the water-energy nexus as a key resource issue for future economic viability.

The delay, in the past, in recognising the economic consequences of a limited water supply, and in decoupling economic development from water demand and supply, has resulted in a water-dependent growth model, currently threatened by increasing scarcity and droughts. Consequently, there is now an urgent need for new perspectives in order to promote a more sustainable and efficient use of water resources. This calls for, on the one hand, a comprehensive understanding of water efficiency and productivity and, on the other hand, an investigation of the linkages among economic sectors to illustrate trade-offs in water reallocations. In addition, this also points to the need to study institutional innovations and economic evaluation instruments able to better assess policy performance and provide evidence for improved mechanism designs aimed specifically at water efficiency and water productivity.

The objective of this special issue on "Water policy, productivity and economic efficiency" is to provide an overview of future perspectives on these issues, in the context of alternative uses and perspective scenarios. This set of papers mainly takes an economic perspective; in this sense, it is intended to be complementary to other disciplinary views and contributing to interdisciplinary approaches, aimed at interpreting the complexity of the relevant social and environmental issues, of great importance for a thorough understanding of the role of water in the welfare of society.

The selected papers cover a wide a range of relevant economic issues, inherently linked to the fact that water is at the heart of sustainable human development and needs to be studied from multiple perspectives. This introductory paper is organised as follows: in Section 2, we briefly outline the main themes from the special issue that have been emphasised in the international literature. Based on this, we then propose a reasoned analysis of the contributions of this special issue (Section 3), as the basis of a discussion of selected future scientific challenges in this field (Section 4). 


\section{Changing Context and Research Challenges}

Integrated water management has been a cornerstone of the water literature and water policy trends for many years. The complexity of integrated water management and the variety of scales and perspectives of analysis was exacerbated at the beginning of this century by a number of issues related to population growth, climate change and resource limitations, in the context of an increasingly complex world economy [5]. For the agricultural sector in particular, which is the most important sector with respect to water use in many countries, the challenge of feeding a growing population has become a key issue in the agenda, while at the same time, the farming sector has proved to be the sector most exposed to climate change [6]. In reconciling these needs, water productivity is a key topic, particularly in water scarce areas (see e.g., [7]). Water also affects the productivity of other resources, such as soil and fertilisers. For agriculture as a whole, in order to face these needs, new productivity-related concepts, such as sustainable intensification, are emerging [8].

A key emerging topic is the water-agriculture-energy nexus (in turn connected to climate change), in which agriculture uses water for food production, as well as for producing feedstocks for renewable energy production, both of which are affected by climate change and, in turn, can affect climate change through emissions of GHG gasses [9]. The development of the bioeconomy could increase the relevancy of this issue by extending the role of agriculture to the production of feedstocks for biobased industries, potentially increasing pressures on water (or dependency on water availability) and trade-offs with other sectors.

In order to come to terms with this context, together with water allocation issues (e.g., minimum vital flow) and supply side measures (e.g., water reservoirs), water policy is increasingly focused on increasing water efficiency [10]. The direction taken by the European Commission is a good example. It has recently developed a comprehensive strategy aimed at improving water efficiency. This strategy provides, in addition to pricing and cost recovery policies, a number of additional actions, such as: "water accounts", at basin and sub-basin levels, to increase the information base on which to build locally specific measures; "water stress targets and indicators", developed for each relevant sector (industry, energy production, agriculture, households, etc.), in order to avoid possible rebound effects; "Eco-Design guidelines", to promote more efficient water devices and products on the market, clearly labelled on the basis of their efficiency; "irrigation efficiency measures" in the CAP, including "minimum water use reductions"; "best practices on Sustainable Economic Leakage Levels" to adapt water infrastructure to climate change; and water trading guidelines, to help the development of water trading in the Member States that choose to employ it [10].

These areas of intervention not only demonstrate the variety and complexity of the issues at stake, but also touch upon a number of open issues for research. An example is the concept of "efficiency and productivity". First, efficiency can have different disciplinary perspectives ranging from crop physiology to economics [11]. Second, different definitions exist of both water productivity and water efficiency and their appropriate application depends on different scales and domains of water use [12,13] and on the different meanings assigned to these concepts [14]. Taking into account these differences in meaning and avoiding an overly standardised and simplified use of these complex concepts would help to minimise the risk of justifying policies and projects that ignore the specificities 
of local contexts and underestimate relevant social and environmental trade-offs between different water uses and different water users.

Another example is that of the different scales and perspectives of analysis. While the farm scale is a typical case for agriculture, attention to agricultural systems is also important, and the basin scale has become a key scale of analysis in order to account for inter-sector connections, whilst maintaining a clear relationship with a meaningful hydrological unit. However, over time, the interconnections among economic activities and the emergence of global phenomena such as climate change have led to an increasing number of modelling exercises using even regional, national or global scales (see e.g., [15-17]). Different scales may yield completely different pictures due to interconnections among sectors, but also highlight the urgency for compensation and displacement effects.

While there are numerous ways to encourage water using sectors to move in the right direction, the key issue is how to make this happen via appropriate incentives that are ultimately connected to policy instruments and governance systems. In particular, both economic policy instruments and appropriate governance settings have attracted the attention of economists in recent years, in part due to the coming into force of major legal instruments promoting tangible change, such as the Water Framework Directive [18].

A good deal of attention has been attracted by putting in place appropriate price setting mechanisms, as a means of incentivizing efficiency in water use [10,19]. Research in this field is still characterised by several open issues and is largely driven by the discrepancy between ideal water prices and actual prices for use (particularly with respect to volumetric pricing).

On the other hand, the changing context referred to above is starting to challenge established ways of looking at water policy. Issues include: the increased dynamics of water use technologies, which is linked to the renewed emphasis on innovation; the need to consider wider economic effects beyond simple profit for businesses, including overall sector viability; the consideration of wider flows of water (e.g., virtual water), the interconnection with social and ethical issues related to water distribution; soft factors such as governance; and social innovation, and uncertainty. Scale is of particular importance as is the consideration of the interlinked effects of different policy areas, which require a comprehensive view of water and the economy as a whole [20].

Based on these innovative themes, which have been progressively grafted onto the more established ones, a non-exhaustive list of relevant topics has been compiled, including: (i) economic analysis of experiences and open issues related to innovative water management for crop production; (ii) the production and efficiency effects of innovative policy instruments and mechanisms; (iii) ex-post and ex-ante policy evaluation approaches, methods and tools, and their application to cost-benefit and cost-effectiveness analyses of water policy measures from the point of view of economic efficiency and productivity; (iv) the efficiency effects of coordination between water policy and specific sector policies; (v) water policy and the viability of economic sectors in the context of drought and climate change management; (vi) water policy and wider economic and social issues; and (vii) water policy and competitiveness.

The proposals submitted partially cover the range of suggested topics. Among these, nine were selected, the contents of which are analysed in the following section. 


\section{The Main Contribution of this Special Issue}

The nine selected works can be divided into three categories, which are the three main areas of the theme "Water Policy, Productivity and Economic Efficiency", namely: "Productivity assessment", "Institutional framework and mechanisms" and "Governance aspects".

The first category is represented by two works on the assessment of water productivity, the first at farm level and the second at the sectorial comparison level. In [21], Wichelns asks whether, given the complexity and uncertainty inherent in the farm's strategic decisions, maximizing the productivity of water is coherent with farm level goals. Based on the analysis of published production functions, he concludes that the estimates of water productivity contain too little information to improve the understanding of water management at the farm level.

In [22], Perez Blanco and Thaler estimate the intertemporal water productivity by way of the Hypothetical Extraction Method. The work confirms the existence of a productivity gap between agriculture and other sectors that are still largely dependent on agricultural production. The results suggest the existence of a "Verdoorn's Law" (a positive relationship between the growth of output and the growth of productivity) effect for water.

The second, and largest, category includes contributions aimed at investigating the issue of the productivity and efficiency of water, with reference to the various policy instruments and allocation mechanisms. These can be defined as the set of institutional frameworks and rules that determine the amount of water that users have the right to use: basically, markets and public administration. Each institutional setting provides water through a pricing mechanism (volumetric, not volumetric, etc.). The interest in this topic is notoriously linked to the fact that water possesses, as an economic good, unique characteristics that make its allocation particularly complicated. This category includes six studies. Two of these are focused on the analysis of efficiency of the institutional framework of the water market. In [23], Ming-Feng Hung et al., using an agent-based model simulation, estimate the potential economic benefits of implementing an innovative system of water trading in the Choushui River basin (Taiwan) where agriculture is highly developed and domestic/industrial water demands have increased rapidly. The particularity of this model stems from the fact that it was designed according to "locational water rights", taking into account the river flow's unidirectionality.

In [24], Zeng et al., develop a two-stage inexact credibility-constrained programming (TICP) method for identifying the efficiency of water trading under multiple uncertainties. On the basis of a real case of water resource allocation management and planning (in the arid region of Kaidu-kongque River Basin, Northwest China), the paper shows that, under some designated situations, trading is much more optimal and effective than non-trading, in terms of economic benefits and in terms of incentives for adopting water saving policies.

The other four papers in this group are placed within the framework of public water in Europe and investigate aspects of water management, more or less closely related to the rules laid down by the Water Framework Directive (WFD) 60/2000.

In [25], Galioto et al., explore how agricultural water pricing could contribute to lowering water demand under asymmetric information (when uses are unobserved). The study applies a Principal-Agent model, implemented as a mathematical non-linear programming model to the pricing policies of a Reclamation and Irrigation Board in Northern Italy. Given the current pricing structure 
and assuming zero transaction costs, the paper compares the performance of both an actual regulator's goals and the cost recovery objective of an ideal regulator driven by WFD principles. The results show a relevant increase in net benefits for the ideal scenario with respect to the actual one as water use costs increase. However, the existence of non-zero transaction costs related to the control of water uses points to the need for further research.

In [26], Galioto et al., develop a procedure consistent with the guidelines of the Directive. The assessment methodology takes into account the interdependencies between water bodies and the interactions between measures and pressures. The cost-effectiveness analysis, integrated into a cost-benefit analysis, makes it possible to select an efficient combination of measures, to evaluate the economic viability of the actions and to identify the areas where disproportionate costs are more likely to occur. Disproportionality tends to increase from foothill regions to plain areas, where the sources of pressure are most frequently located.

In [27], Giraldo et al., evaluate the implementation of a volumetric and cost-recovery pricing method for irrigation water under symmetric information conditions. In the first step, a cost function (translog) was estimated for irrigation water supplied by a water user association to a typical Mediterranean agricultural area. In the second step, the economic impact of a pricing method designed according to this cost function was simulated using a mathematical programming territorial model for the same agricultural area. The authors conclude that a performance assessment of pricing methods must take into account differences in implementation costs, as it is possible that an inefficient per-area pricing method could outperform an efficient volumetric pricing method.

In the sixth and final paper of this group, which is mainly a methodological one [28], Christos Mattas et al., adopt the DPSIR (Driving forces, Pressures, States, Impacts, Responses) framework to investigate the main causes and origins of pressures (overexploitation of aquifers, water quality degradation, and decreases in river discharge) to optimize the measures for sustainable management of water resources in that basin. The application of the DPSIR analysis links the socioeconomic drivers to the water resource pressures, the responses based on the WFD and the national legislation, hence demonstrating that this model is a useful tool for land-use planning and decision making in the area of water protection.

The third category includes the study of Asquer, who investigates various less-studied issues related to governance in the water sector. In [29], the author explores the behaviour of institutions responsible for the regulation of water services at the local level. In particular, using a Q-methodology on the opinions expressed by elected public officials, this study shows the multiplicity of subjective points of view regarding the design of local water policies in Italy. It helps to explain the frequent changes and instability in the overall regulatory design including, for example, the formulation of tariff rules.

\section{Final Remarks and Outlook}

The main messages from this special issue reinforce several well-established notions about current research in the field of water policy. In the face of a number of major world challenges, new solutions must be sought for water management. Such solutions must go beyond the traditional trade-off between economic and environmental values in order to find innovative solutions to reconcile productive/economic aims and environmental/resource conservation objectives. 
A number of new concepts are emerging in this direction, including sustainable intensification and the quest for win-win solutions. The pathway is not straightforward, yet some specific research challenges may be identified from the collection of papers in this special issue, along the same lines as the classification of papers reported above.

First, there is the issue of properly representing technologies linking water and its physical productivity. Even basic concepts in economics (such as production functions) are not easily usable when it comes to numerical exercises, largely due to the lack of data, but also because of the difficulties in capturing variability over time and space for the actual performance of technology. In addition, the prominence of technological innovation tends to accelerate the pace of change of such relationships. The solutions to this challenge seem to rest in a mix of awareness of the basics (e.g., well established analysis tools and theory, transparent assumptions and first-hand experience of reality) and new techniques to account for dynamics and variability, or to measure relevant relationships.

Second, there is the challenge of attaching economic values to water uses, given their connection to monetary or non-monetary evaluations of non-market goods, or to the economic effects of water use throughout the economy. As this is strictly connected to the provision of proper incentives, it is clearly a major point of departure for economic research related to policy design and decision making. However, it is also connected to the significant challenge inherent in policy analysis, which is to properly represent agents' behaviour and the effects of policy on this behaviour. The existing analyses concerning the water sector seem to suffer from the simplification of neoclassical approaches and challenges when seeking appropriate solutions to better represent the real world.

Third is the issue of achieving results through appropriate governance at different levels and the integration of different stakeholders' viewpoints, and which ultimately goes beyond economic values and social, political and ethical issues. In spite of the emphasis given to participatory processes in water-related decision-making, research on appropriate procedures and tools is lacking.

From the point of view of economic research, the challenge is the growing need to address these three challenges contemporaneously. This justifies increased attention being dedicated to mixed-method approaches and the use of integrated modelling approaches.

Even in the absence of concerted efforts, individual studies increasingly emphasise the tension between very specialised and focused tools, very specific policy mechanisms and maintaining a clear vision of the overall picture. This will likely remain a distinct feature of water policy research in the years to come.

\section{Acknowledgments}

The authors of this paper and the editors of the special issue wish to thank the journal editors, all authors submitting papers and the referees who have contributed to paper selection and improvement. However, the usual disclaimer applies.

\section{Conflicts of Interest}

The authors declare no conflict of interest. 


\section{References}

1. World Meteorology Organization (WMO). The Dublin Statement on Water and Sustainable Development. 2007. Available online: https:/www.wmo.int/pages/prog/hwrp/documents/ english/icwedece.html (accessed on 1 September 2014).

2. United Nations (UN). Rio Declaration on Environment and Development, UN Doc. A/CONF.151/26 (vol. I)/31 ILM 874, 1992.

3. Dinar, A.; Saleth, R.M. Issues in Water Pricing Reforms: From Getting Correct Prices to Setting Appropriate Institutions. In The International Yearbook of Environmental and Resource Economics 2005/2006; Folmer, H., Titenberg, T., Eds.; Edward Elgar: Cheltenham, UK, 2005.

4. Dudu, H.; Chumi, S. Economics of Irrigation Water Management: A Literature Survey with Focus on Partial and General Equilibrium Models; Policy Research Working Paper 4556; The World Bank: Washington, DC, USA, March 2008.

5. Bouwer, H. Integrated Water Management for the 21st Century: Problems and Solutions. J. Irrig. Drain Eng. 2002, 128, 193-202.

6. Godfray, H.C.J.; Beddington, J.R.; Crute, I.R.; Crute, I.R.; Haddad, L.; Lawrence, D.; Muir, J.F.; Pretty, J.; Robinson, S.; Thomas, S.M.; et al. Food security: The challenge of feeding 9 billion people. Science 2010, 327, 812-818.

7. Qadir, M.; Noble, A.D.; Chartres, C. Adapting to Climate Change by Improving Water Productivity of Soils in Dry Areas. Land Degrad. Dev. 2013, 24, 12-21.

8. Schulte, R.P.O.; Creamer, R.E.; Donnellan, T.; Farrelly, N.; Fealy, R.; O’Donoghue, C.; O'hUallachain, D. Functional land management: A framework for managing soil-based ecosystem services for the sustainable intensification of agriculture. Environ. Sci. Policy 2014, 38, 45-58.

9. OECD. Climate Change, Water And Agriculture: Towards Resilient Agricultural And Water Systems, COM/TAD/CA/ENV/EPOC(2013)21/FINAL, 2014.

10. European Commission. A Blueprint to Safeguard Europe's Water Resources, COM(2012) 673 final, Brussels, Belgium, 2012.

11. Nair, S.; Johnson, J.; Wang, C. Efficiency of Irrigation Water Use: A Review from the Perspectives of Multiple Disciplines. Agron. J. 2013, 105, 351-363.

12. Van Halsema, G.E.; Vincent, L. Efficiency and productivity terms for water management: A matter of contextual relativism versus general absolutism. Agric. Water Manag. 2012, 108, 9-15.

13. Kambou, D.; Xanthoulis, D.; Ouattara, K.; Degré, A. Concepts d'efficience et de productivité de l'eau (synthèse bibliographique). Biotechnol. Agron. Soc. Environ. 2014, 18, 108-120.

14. Boelens, R.; Vos, J. The danger of naturalizing water policy concepts: Water productivity and efficiency discourses from field irrigation to virtual water trade. Agric. Water Manag. 2012, 108, 16-26.

15. Berrittella, M.; Hoekstra, A.Y.; Rehdanz, K.; Roson, R.; Tol, R.S.J. The economic impact of restricted water supply: A computable general equilibrium analysis. Water Res. 2007, 41, 1799-1813.

16. González, J.F. Assessing the Macroeconomic Impact of Water Supply Restrictions through an Input-Output Analysis. Water Resour. Manag. 2011, 25, 2335-2347.

17. Luckmann, J.; Grethe, H.; McDonald, S.; Orlov, A.; Siddig, K. An integrated economic model of multiple types and uses of water. Water Resour. Res. 2014, 50, 3875-3892. 
18. European Commission. Directive 2000/60/EC (Water Framework Directive); Official of the European Communities: Brussels, Belgium, 2000.

19. Johansson, R.C.; Tsur, Y.; Roe, T.L.; Doukkali, R.; Dinar, A. Pricing Irrigation Water: A review of theory and practice. Water Policy 2002, 4, 173-179.

20. Dinar, A. Water and Economy-Wide Policy Interventions. Found. Trends ${ }^{\circledR}$ Microecon. 2014, 10, 85-165, doi:10.1561/0700000059.

21. Wichelns, D. Do Estimates of Water Productivity Enhance Understanding of Farm-Level Water Management? Water 2014, 6, 778-795.

22. Perez Blanco, C.D.; Thaler, T. An Input-Output Assessment of Water Productivity in the Castile and León Region (Spain). Water 2014, 6, 929-944.

23. Hung, M.-F.; Shaw, D.; Chie, B.-T. Water Trading: Locational Water Rights, Economic Efficiency, and Third-Party Effect. Water 2014, 6, 723-744.

24. Zeng, X.; Li, Y.; Huang, G.; Yu, L. Inexact Mathematical Modeling for the Identification of Water Trading Policy under Uncertainty. Water 2014, 6, 229-252.

25. Galioto, F.; Raggi, M.; Viaggi, D. Pricing Policies in Managing Water Resources in Agriculture: An Application of Contract Theory to Unmetered Water. Water 2013, 5, 1502-1516.

26. Galioto, F.; Marconi, V.; Raggi, M.; Viaggi, D. An Assessment of Disproportionate Costs in WFD: The Experience of Emilia-Romagna. Water 2013, 5, 1967-1995.

27. Giraldo, L.; Cortignani, R.; Dono, G. Simulating Volumetric Pricing for Irrigation Water Operational Cost Recovery under Complete and Perfect Information. Water 2014, 6, 1204-1220.

28. Mattas, C.; Voudouris, K.S.; Panagopoulos, A. Integrated Groundwater Resources Management Using the DPSIR Approach in a GIS Environment Context: A Case Study from the Gallikos River Basin, North Greece. Water 2014, 6, 1043-1068.

29. Asquer, A. Understanding Subjectivities in the Regulation of Local Water Services: A Q-Methodology Study of Elected Public Officers in Italy. Water 2014, 6, 670-693.

(C) 2014 by the authors; licensee MDPI, Basel, Switzerland. This article is an open access article distributed under the terms and conditions of the Creative Commons Attribution license (http://creativecommons.org/licenses/by/4.0/). 